\title{
Asphyxia as a Risk Factor for Neonatal Hypoglycemia
}

\author{
Luthfina Mufidati ${ }^{1}$, Alifah Anggraini ${ }^{2}$, Tunjung Wibowo ${ }^{3}$
}

\begin{abstract}
Introduction: Hypoglycemia leads to brain developmental disturbances and abnormality on its function. Perinatal stress including asphyxia is a significant cause of neonatal hypoglycemia, thus, it is important to prevent it by controlling its relevant confounding variables. The aims of this study were to identify the risk factors of neonatal hypoglycemia and its related variables, focusing on the role of asphyxia in neonatal hypoglycemia. Material and Methods: We conducted a nested case control study using a cohort data from South East Asia Regional Neonatal-Perinatal Database year 2013 of the Maternal and Perinatal Unit, Dr. Sardjito General Hospital Yogyakarta. We randomly selected neonatal hypoglycemia as a case and neonatal without hypoglycemia as a control group. We identify the risk factors from the cohort data. Logistic regression analyses were performed to investigate the association between hypoglycemia and risk factors. Results: A total of 1563 newborns were recruited in this study. Five hundred and twenty newborns were excluded due to incomplete data and major congenital anomalies. By simple randomization sampling, we selected 52 newborns in cases group and 104 newborns in control group. In multivariate models, being asphyxia, low birth weight (LBW), large for gestational age (LGA), and early onset of neonatal sepsis showed significant effects on risk of hypoglycemia, OR= 2.8 (95\% Cl: $1.01-7.80)$, OR 7.1 (95\% Cl 1.54-32.37), OR 37.2 (95\% Cl 6.28-219.85), and OR 40.6 (95\% Cl 10.84-152.01), respectively. Conclusion: Asphyxia, LBW, LGA and early onset neonatal sepsis were significant risk factor for neonatal hypoglycemia.
\end{abstract}

Key words: Asphyxia, Hypoglycemia, Neonates, Risk factor

\section{Introduction}

$\mathrm{R}^{\mathrm{c}}$ ecurrent hypoglycemia may impair brain function and child development, lateron. Long-termsequelaeofseverehypoglycemia were recurrent seizure and mental retardation. Permanent defect of the brain may develop after hypoglycemia ${ }^{1}$. Perinatal stress including neonatal asphyxia is one of important cause of hypoglycemia ${ }^{2,3}$. Neonatal asphyxia is related to excessive glycogenolysis leading
${ }^{1}$ Dr. Luthfina Mufidati, Medical Student, Medical School, Universitas Gadjah Mada, Indonesia, ${ }^{2}$ Dr. Alifah Anggraini, Division of Neonatology, Department of Child Health, Medical School, Universitas Gadjah Mada/ Sardjito Hospital, Yogyakarta, Indonesia, ${ }^{3} \mathrm{Dr}$. Tunjung Wibowo, Division of Neonatology, Department of Child Health, Medical School, Universitas Gadjah Mada/ Sardjito Hospital, Yogyakarta, Indonesia.

\section{Address for correspondence}

Dr. Tunjung Wibowo, MPH, Paediatrician, Consultant in Neonatology,

Division of Neonatology, Department of Child Health, Medical School, Universitas Gadjah Mada/ Sardjito Hospital,

Yogyakarta, Indonesia

Tel No; +62 8562852766

E-mail: tunjungwibowo@gmail.com

Acknowledgements: We would like to thank the WHO SEARO office which provide funding for neonatal-perinatal database collection.

Funding: Partial funding by WHO (SEARO), New Delhi.

Conflict of Interest: None

Permission from IRB: Yes

\section{How to cite}

Luthfina Mufidati, Alifah Anggraini, Tunjung Wibowo. Asphyxia as a Risk Factor for Neonatal Hypoglycemia. J Nepal Paediatr Soc 2017;37(2):111-116.

doi:http://dx.doi.org/10.3126/jnps.v37i2.16581

This work is licensed under a Creative Commons Attribution 3.0 License. 
to the decrease of glycogen storage. Continuously high insulin release due to asphyxia causing extreme fatigue and damage in b-cell of pancreas. This condition often results in hypoglycemia ${ }^{4}$. Capacity of a newborn in maintaining glucose homeostasis is limited due to metabolic transition ${ }^{5}$. Nowadays, early diagnosis and treatment of neonatal hypoglycemia is considered to be the best choice in preventing further brain damage ${ }^{4}$. Therefore, identifying preventable risk factors minimizes the negative impacts of neonatal hypoglycemia on the child's growth and development.

The aims of this study were to identify the risk factors of neonatal hypoglycemia and its related variables, focusing on the role of asphyxia in neonatal hypoglycemia.

\section{Material and Methods}

A nested case-control study using WHO - South East Asia Regional Neonatal-Perinatal Database was conducted at Maternal Perinatal Unit, Dr. Sardjito General Hospital, Yogyakarta from January until December 2013. Newborn with and without hypoglycemia who admitted into Perinatal ward or Neonatal Intensive Care Unit at Dr. Sardjito General hospital were considered as research subject.

Newborns without any major congenital anomaly were further classified into case and control group. Neonatal hypoglycemia was confirmed if the blood glucose levels $<45 \mathrm{mg} / \mathrm{dL}$. Neonates diagnosed with hypoglycemia were then classified into the case group, and those who weren't, into the control group. The subject will be included in the case group if hypoglycemia were diagnosed and major congenital anomalies were not found. Those who were in the control group did not experience hypoglycemia and any major congenital anomalies. The exclusion criterias were incomplete data, neonates weighing 500 grams or less at birth, or left against medical advice.

The diagnosis of asphyxia was made if the neonate's one-minute APGAR score was $\leq 7^{22}$. We included in the analysis 14 confounders, namely multiple fetus, large for gestational age, small for gestational age, premature rupture of the membrane, prematurity, low birth weight, early onset neonatal sepsis, placenta previa, Caesarean section, pre-eclampsia or eclampsia, respiratory distress syndrome, congenital heart disease, meconium aspiration syndrome, and maternal diabetes.

Sample size was calculated with statistical power=0.8, a=0.05, proportion of hypoglycemia among asphyxiated newborn $=0.3^{6}$, and proportion of hypoglycemia among non-asphyxiated newborn $=14 \%{ }^{7,8}$.
The collected data was then transferred into a computerized-database. Periodical data checking was done to ensure the validity of the data. Statistical analysis used were Chi-square test to calculate the proportional difference and Odds Ratio (OR) with 95\% Confidence Interval $(\mathrm{Cl})$ to determine the relationship between variables. Multivariate analysis was also performed to control the confounding variables. Ethical approval was given by the Research Ethic Committee of Universitas Gadjah Mada Medical School and Dr. Sardjito General Hospital Yogyakarta, Indonesia.

\section{Results}

A total of 1562 live births were recruited to this study (Figure 1). Five hundreds and twenty $(33,3 \%)$ were excluded due to major congenital anomalies and incomplete data. There were 234 (22.5\%) newborns with hypoglycemia and 385 (36.9\%) newborns with asphyxia. By using simple randomization methods, we had 52 newborns with hypoglycemia on case group and 104 newborns without hypoglycemia on control group. Baseline characteristics of the newborns in the two groups are shown in Table 1. Overall, the mean birth weight and gestational age of newborns with hypoglycemia was lower compared to newborns without hypoglycemia (2283.4 g vs. 2788.0 g; 35.7 vs. 37.7 weeks, respectively). All deliveries were attended by doctors. Apgar score $<7$ were more commonly found in newborns with hypoglycemia than those without hypoglycemia ( $52 \%$ vs. $31.8 \%$ ).

The results of the bivariate and multivariate analysis for hypoglycemia risk factors are shown in Table 2. Placenta previa, premature rupture of membrane, congenital heart disease, and infants of diabetic mothers were not included into bivariate analysis because the number of the subjects were too small. Asphyxia, LBW, SGA, LGA, prematurity, pre-eclampsia/ eclampsia, meconium aspiration syndrome, RDS, and early onset neonatal sepsis had $P$ value $<0.2$ and thus were included into multivariate analysis model. The multivariate analysis result showed that asphyxia, LBW, LGA, and early onset neonatal sepsis were significant risk factors for neonatal hypoglycemia.

\section{Discussion}

Our study demonstrated that mean plasma glucose level was lower in newborns with asphyxia. Other studies reported similar results ${ }^{3,9}$. Basu et al., reported that the severity of asphyxia was directly proportional to the degree of hypoglycemia ${ }^{3}$. Our study also indicated that higher proportion of hypoglycemia were found among newborns diagnosed with asphyxia (67.3\% vs $32.7 \%)$. 


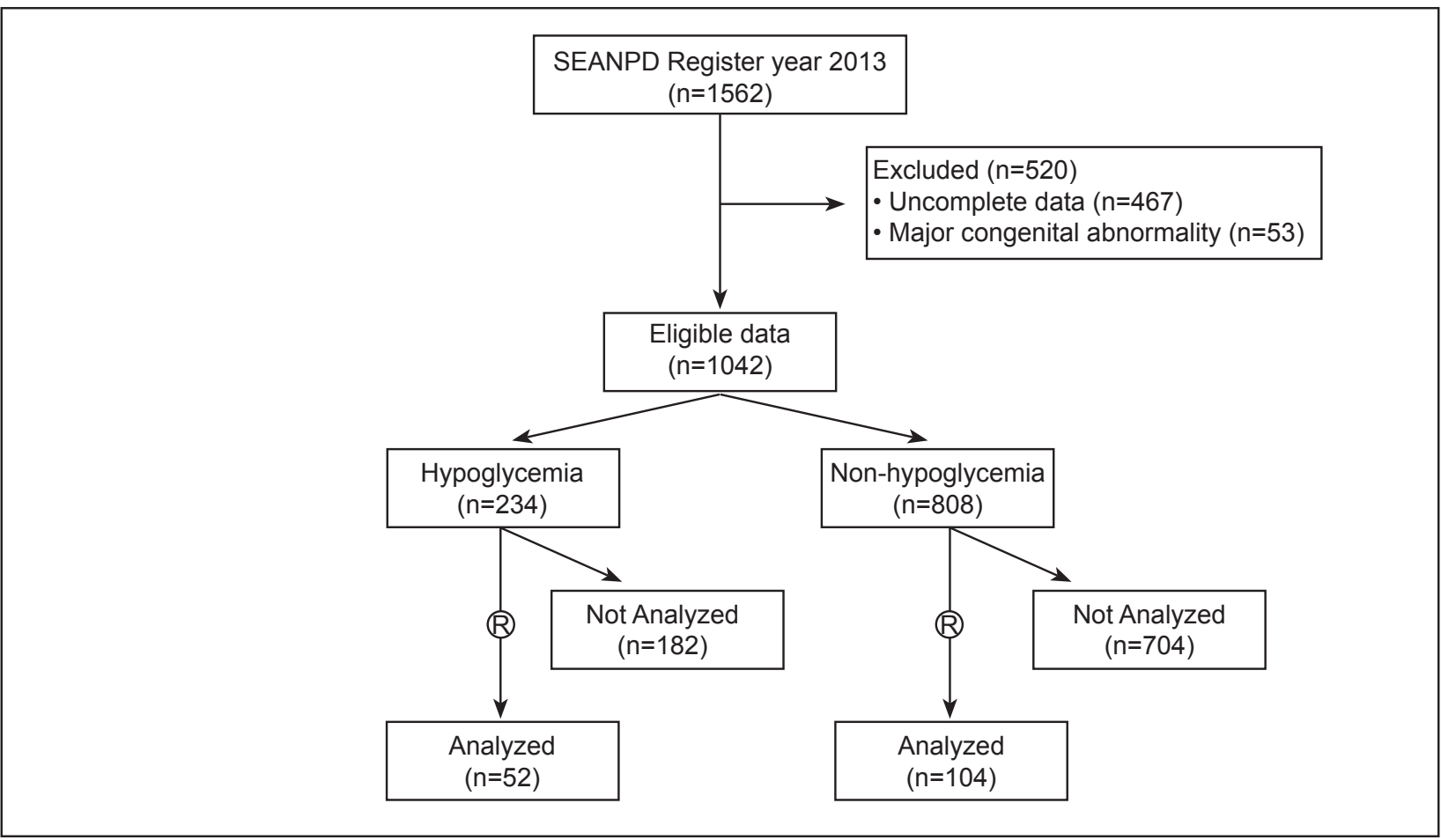

Fig 1: Subjects recruitment flowchart

Table 1. Baseline characteristics

\begin{tabular}{|c|c|c|}
\hline Characteristics & $\begin{array}{c}\text { Hypoglycemia } \\
n=52\end{array}$ & $\begin{array}{c}\text { Non-hypoglycemia } \\
n=104\end{array}$ \\
\hline Male & $29(\% 55.8)$ & $55(\% 52.9)$ \\
\hline Female & $23(\% 44.2)$ & $49(\% 47.1)$ \\
\hline Birth weight, g, mean (SD) & $2283.4(908.9)$ & $2788.0(630.8)$ \\
\hline Birth length, cm, mean (SD) & $43.8(4.4)$ & $46,6(3.8)$ \\
\hline Head circumference, $\mathrm{cm}$, mean (SD) & $31,6(2.9)$ & $33.0(2.4)$ \\
\hline Gestational age, week, mean (SD) & $35.7(3.6)$ & $37.7(2.9)$ \\
\hline Spontaneous delivery & $24(\% 46.2)$ & $39(\% 37.5)$ \\
\hline Caesarean section & $25(\% 48.1)$ & $59(\% 56.7)$ \\
\hline Other mode of deliveries & $3(\% 5.8)$ & $6(\% 5.8)$ \\
\hline Gave birth attended by doctor & $52(\% 100)$ & $104(\% 100)$ \\
\hline 1-minute Apgar score: 7-10 & $17(\% 32.7)$ & $50(\% 48.1)$ \\
\hline 1-minute Apgar score: 4-6 & $20(\% 38.5)$ & $28(\% 27.0)$ \\
\hline 1-minute Apgar score: 0-3 & $7(\% 13.5)$ & $5(\% 4.8)$ \\
\hline 5-minute Apgar score: 7-10 & $7(\% 13.5)$ & $4(\% 3.8)$ \\
\hline 5-minute Apgar score: 4-6 & $3(\% 5.7)$ & $6(\% 5.8)$ \\
\hline 5-minute Apgar score: 0-3 & $3(\% 5.8)$ & $1(\% 1.0)$ \\
\hline Gravida, mean (SD) & $1.9(1.0)$ & $2.1(1.1)$ \\
\hline Para, mean (SD) & $0.7(0.8)$ & $0.9(0.9)$ \\
\hline Abortus, mean (SD) & $0.2(0.4)$ & $0.2(0.5)$ \\
\hline Stillbirth, mean (SD) & $0(0)$ & $0,01(0,098)$ \\
\hline Antenatal care $\geq 3$ & $51(\% 98.1)$ & $102(\% 98.1)$ \\
\hline Antenatal care $<3$ & $1(\% 1.9)$ & $2(\% 1.9)$ \\
\hline
\end{tabular}


Table 2: Risk factors for neonatal hypoglycemia

\begin{tabular}{|c|c|c|c|c|c|c|}
\hline \multirow{2}{*}{ Risk factors } & \multirow{2}{*}{ Frequency } & \multicolumn{3}{|c|}{ Univariate analysis } & \multicolumn{2}{|c|}{ Multivariate analysis } \\
\hline & & OR & $95 \% \mathrm{Cl}$ & $\mathbf{P}$ & OR & $95 \% \mathrm{Cl}$ \\
\hline Asphyxia & $71(\% 45.5)$ & 3.9 & $1.92-7.88$ & $<0.001$ & 2.8 & $1.01-7.80$ \\
\hline Low birth weight & $62(\% 39.7)$ & 5.9 & $2.84-12.14$ & $<0.001$ & 7.1 & $1.54-32.37$ \\
\hline SGA & $40(\% 25.6)$ & 4.4 & $1.05-18.33$ & 0.042 & 1.0 & $0.24-4.06$ \\
\hline LGA & $9(\% 5.8)$ & 2.3 & $1.09-4.77$ & 0.029 & 37.2 & $6.28-219.85$ \\
\hline Prematurity & $52(\% 33.3)$ & 3.4 & $1.69-6.91$ & 0.001 & 0.5 & $0.12-1.94$ \\
\hline Caesarean section & $84(\% 53.8)$ & 0.7 & $0.36-1.38$ & 0.308 & - & - \\
\hline Twin birth & $18(\% 11.5)$ & 1.3 & $0.48-3.62$ & 0.596 & - & - \\
\hline Preeclampsia/ eclampsia & $20(\% 12.8)$ & 2.2 & $0.87-5.78$ & 0,096 & 2.7 & $0.66-11.38$ \\
\hline $\begin{array}{l}\text { Meconium aspiration } \\
\text { syndrome }\end{array}$ & $4(\% 2.6)$ & 6.3 & $0.64-62.19$ & 0.115 & 0.2 & $0.01-3.07$ \\
\hline RDS & $7(\% 4.5)$ & 5.4 & $1.02-28.99$ & 0.048 & 1.5 & $0.14-15.98$ \\
\hline Early onset neonatal sepsis & $37(\% 23.7)$ & 31.7 & $11.0-91.25$ & $<0.001$ & 40.6 & $10.84-152.01$ \\
\hline
\end{tabular}

Asphyxia as a risk factor for neonatal hypoglycemia was also reported by other researchers. However, the magnitude of that risk was not indicated in the previous study $^{10}$. Hypoglycemia caused by asphyxia can be explained by several mechanisms. During asphyxia, anaerobe glycolysis process results in the production of 2 molecules of adenosine triphosphate (ATP) from each molecule of glucose, instead of 38 ATP which usually were produced during aerobic condition. Anaerobic glycolysis elevates lactic acid production. Severe acidosis, on the other hand, diminishes glycolysis, causes loss of cardiovascular autoregulation, and decreases cardiac function. Furthermore, this process results in local ischemia and limitation in glucose transportation $^{3}$. The unexplained catecholamine release and hyperinsulinemia will decrease glycogen storage ${ }^{9}$. Newborn with asphyxia demonstrates higher blood insulin levels within first 24 and 72 hours of life, which potentially suppress hepatic glycogenolysis response ${ }^{11}$. Besides that, hypoxia of the brain increases glucose consumption. Compared with adult brain, an immature brain of low birth weight infant is more resistant to injury caused by hypoxia. Moreover, combined hypoglycemia and asphyxia results in the failure of compensatory mechanism to save the brain from damage due to persistent hypoxia ${ }^{3}$.

Male infants in our study experienced more hypoglycemia and asphyxia compared to female. Other study supported our result, and the researchers argued that hormonal system of male infants were less likely to be more mature than females'. There was also reported that they had such different enzymatic responses towards ketogenesis ${ }^{12}$.

Low birth weight as a risk factor of hypoglycemia is also reported by other studies. De et al. demonstrated higher hypoglycemia prevalence among low birth weight infants compared to normal birth weight newborn. Moreover, mean of blood glucose levels of low birth weight infants were lower than normal weight infants at 1 , 6,12 , and 24 hour(s) after birth ${ }^{13}$. Other study reported a high prevalence $(52 \%)$ of hypoglycemia among low birth weight infant and newborn with birth weight less than $10^{\text {th }}$ percentile ${ }^{14}$. In order to maintain the normoglycemic condition, newborn needs sufficient glycogen storage, maturation of glycogenolytic and gluconeogenic pathway, as well as integration of endocrine response. The increase of adrenalin secretion and rapid decrease of insulin-glucagon ratio within the first hour of life, stimulate glucose release and fat metabolism from peripheral storage ${ }^{13}$.

The study result from Esakof et al. supported ours. Newborns with birth weight $\geq 4000 \mathrm{~g}$ had higher risk of getting hypoglycemia compared with those whose birth weight $<4000 \mathrm{~g}$. Maternal gestational diabetes increased the risk of LGA. The incidence of hypoglycemia within first hour of life was more common in neonates born from mothers with gestational diabetes ${ }^{16}$. Several extrinsic factors influencing birth weight were smoking mother, viral infection, diabetes and hypertension. Other factors such as maternal height, BMI, weight gain during pregnancy may also influence it. Genetic factor and excessive nutrient intake may exaggerate infant growth $^{16}$. LGA infants form non-diabetic mothers may experience transient hypoglycemia, especially those whose mothers are obese. However, the mechanism is still unclear. It is likely that hyperinsulinism is not a major factor ${ }^{5}$.

Our study demonstrated that early onset of neonatal sepsis was also a risk factor of neonatal hypoglycemia. Campos et al. reported that $99 \%$ of newborn with sepsis 
had abnormal blood glucose levels, $58 \%$ of them were hypoglycemic ${ }^{17}$. Neonatal sepsis influences blood glucose levels through several mechanisms. Newborns presenting with sepsis experience feeding difficulties, increase of metabolic demands, and hypothermia ${ }^{18}$. Moreover, sepsis correlates with the increase metabolic rate and risk of toxic effect on liver metabolism, which then results in hypoglycemia ${ }^{4}$.

The risk of hypoglycemia among premature infants as seen in our study can be explained through several reasons. Premature infant has minimal brown fat compared to the mature infants, immature central nerve system, delayed response on hypercarbia, hypotonia of the upper respiratory muscles, less energy storage, and immature mechanism of glucose regulation ${ }^{19}$. The delay of glucose-6-phosphate activity results in abnormality of glycogenolysis and gluconeogenesis response. Minimal oral or enteral intake due to weakness of sucking and swallowing reflexes and immaturity of gastrointestinal system are other problems which may increase the risk $^{20}$.

The role of prematurity as a significant risk factor which showed in bivariate analysis was not further proved in multivariate analysis. We argue that $80.8 \%$ of premature infants in our study were low birth weight. Therefore, risk of prematurity on neonatal hypoglycemia actually reflects the risk of low birth weight itself. In our study, low birth weight increases risk for neonatal hypoglycemia by 7.1 times compared with normal birth weight.
One of our study limitation is the application of Apgar score to define asphyxia rather than blood gas analysis. Using only Apgar score as diagnosis criteria of asphyxia raised a controversy. Apgar score $\geq 7$ usually indicates a rigorous condition ${ }^{21}$ predicting infants' future health status, instead of confirming asphyxia. The type of congenital heart disease that had been registered was only patent ductus arteriosus. The data did not reflect the spectrum of congenital heart disease. The timing of blood sampling for detection of hypoglycemia was not recorded. Consequently, no exact time of the occurrence of hypoglycemia was available. The number of subjects with placenta previa, premature rupture of the membrane, meconium aspiration syndrome, RDS, congenital heart disease, and maternal diabetes were small which raises the possibility of unrepresentative results.

However, our study has a strength. We analyzed 14 potential confounders. The residual confounders in our study is unlikely to be found. Therefore, the role of asphyxia as a risk factor for neonatal hypoglycemia as seen in our study is a strong evidence. The significant relationship between confounders, i.e. LBW, LGA, and early onset of neonatal sepsis and neonatal hypoglycemia indicates that these confounders are also significant risk factors for neonatal hypoglycemia.

\section{Conclusion}

Asphyxia is a risk factor for neonatal hypoglycemia, as well as LBW, LGA and early onset of neonatal sepsis.

\section{References}

1. Kliegman, RM, Behrman, RE, Jenson, HB \& Stanton, BF 2007, Nelson Textbook of Pediatrics, $18^{\text {th }}$ ed., Saunders Elsevier, Philadelphia.

2. Yap F, Högler W, Vora A, Halliday R, Ambler G. Severe transient hyperinsulinaemic hypoglycaemia: two neonates without predisposing factors and a review of the literature. Eur J Pediatr 2004;163:38-41.

3. Basu P, Som S, Choudhuri, Das H. Contribution of the blood glucose level in perinatal asphyxia. Eur $\mathrm{J}$ Pediatr 2009;168:833-38.

4. Arya VB, Senniappan S, Guemes M, Hussain K. Neonatal hypoglycemia. Indian J Pediatr 2013;81:5865.

5. MacDonald MG, Seshia MMK, Mullett MD. Avery's Neonatalogy, $6^{\text {th }}$ ed., Lippincott Williams \& Wilkins, Philadelphia, 2005.

6. Yaseen HA,Al-Najashi SS, Adel AA, Bahnassy AA, Al-Umran KU, Al-Faraidy AA. Predictive factors and incidence of complications in apparently healthy full term infants of diabetic mothers. J Family Community Med 1999;6:37-42.

7. Pal DK, Manandhar DS, Rajbhandari S, Land JM, Patel N, de L Costello AM. Neonatal hypoglycaemia in Nepal 1. Prevalence and risk factors. Arch Dis Child Fetal Neonatal Ed 2000;82:F46-F51.

8. Nadeem M, Murray DM, Boylan GB, Dempsey EM, Ryan CA. Early blood glucose profile and neurodevelopmental outcome at two years in neonatal hypoxic-ischaemic encephalopathy. BMC Pediatr 2011;11:10.

9. Rai S, Bhatiyani KK, Kaur S. Effect of birth asphyxia on serum calcium and glucose level: a prospective study. Int J Sci Stud 2015;3:3-6.

10. Sasidharan CK, Gokul E, Sabitha S. Incidence and risk factors for neonatal hypoglycaemia in Kerala, India. Ceylon Med J 2004;49:110-13.

11. Davis DJ, Creery WD, Radziuk J. Inappropriately high plasma insulin levels in suspected perinatal asphyxia. Acta Pediatr 1999;88:76-81. 
12. Costello AML, Pal DK, Manandhar DS, Rajbhandari S, Land JM, Patel N. Neonatal hypoglycaemia in Nepal 2. Availability of alternative fuels. Arch Dis Child Fetal Neonatal Ed 2000;82:F52-F58.

13. De AK, Biswas R, Samanta M, Kundu CK. Study of blood glucose level in normal and low birth weight newborns and impact of early breast feeding in a tertiary care center. Ann Nigerian Med 2011;5:53-58.

14. Harris DL, Weston PJ, Harding JE. Incidence of neonatal hypoglycemia in babies identified as at risk. $J$ Pediatr 2012;161:787-91.

15. Esakof TF, Cheng YW, Sparks TN, Caughey AB. The association between birthweight $4000 \mathrm{~g}$ or greater and perinatal outcomes in patients with and without gestational diabetes mellitus. Am J Obstet Gynecol 2009;200:672.e1-672.e4.

16. Onal EE, Hirfanoglu IM, Beken S, Altunas N, Turkyilmaz $\mathrm{C}$, Camurdan $\mathrm{AY}$ et al. Are the neonatal outcomes similar in large-for-gestational age infants delivered by woman with or without gestational diabetes mellitus? World J Pediatr 2012;8:136-39.

17. Campos DP, Silva MV, Machado JR, Castellano LR, Rodrigues V, Barata $\mathrm{CH}$. Early-onset, neonatal sepsis: cord blood cytokine levels at diagnosis and during treatment. J Pediatr (Rio J) 2010;86:509-14.

18. Ahmad S, Khalid R. Blood glucose levels in neonatal sepsis and probable sepsis and its association with mortality. J Coll Physicians Surg Pak 2014;22:15-18.

19. Femitha $P$, Bhat BV. Early neonatal outcome in late preterm. Indian J Perdiatr 2012;79:1019-24.

20. Laptook A, Jackson GL. Cold stress and hypoglycemia in the late preterm ("near term") infant: impact on nursery of admission. Semin Perinatol 2006;30:24-27.

21. Leuthner SR, Das UG. Low Apgar scores and the definition of birth asphyxia. Pediatr Clin N Am 2004; 51:737-45.

22. WHO. International statistical classification of diseases and related health problems: $10^{\text {th }}$ revision. 2016;2. 